\title{
HERBAL MEDICINES AS NEUROPROTECTIVE AGENT: A MECHANISTIC APPROACH
}

\author{
SUPRIYA ROY, HIMANI AWASTHI
}

Amity Institute of Pharmacy, Amity University, Lucknow Campus, Uttar Pradesh 226028, India

Email: himani1july@gmail.com

Received: 27 Apr 2017 Revised and Accepted: 21 Sep 2017

\begin{abstract}
Neurodegeneration refers to a condition of neuronal death occurring as a result of progressive disease of long-term and is becoming a major health problem in the 21st century. Neurons degenerated are not replaced resulting in a cognitive loss, many neurodegenerative disorders, such as schizophrenia, depression, Alzheimer's disease (AD), dementia, cerebrovascular impairment, seizure disorders, head injury, parkinsonism. The common pathology of neurodegeneration includes deposition of misfolded proteins such as amyloid- $\beta(A \beta)$ in Alzheimer's disease, $\alpha$-synuclein in Parkinson's disease (PD), transactive response DNA-binding protein 43 (TDP-43) in dementia. Neuroprotection refers to the strategies and possible mechanisms that are able to protect the central nervous system (CNS) against neuronal injury and neurodegenerative disorders. The past decade has witnessed an intense interest in herbal plants having long-term health-promoting or medicinal qualities. Comprehensive research and discovery have demonstrated that natural products, medicinal herbs, plant extracts, and their metabolites, have great potential as the neuroprotective agent. Although the precise mechanisms of action of herbal drugs have yet to be determined, some of them have been shown to prevent formation of betaamyloid plaques, promote nerve growth, some inhibit acetylcholinesterase (AChE) enzyme and malondialdehyde (MDA) formation in brain while other exhibits antioxidant activity by increasing the level of superoxide dismutase (SOD), catalase (CAT), glutathione peroxidase (GPx). Thus the herbal plants can be a valuable source of the drug against neurodegenerative disorders which will require high-throughput screening. This review will highlight the role of herbal plants and their phytoconstituents against neurodegenerative diseases and other related disorders, focusing on their mechanism of action and therapeutic potential.
\end{abstract}

Keywords: Alzheimer's disease, Amyloid- $\beta$, Antioxidant, Dementia, Herbal medicine, Neurodegenerative diseases, Neuroprotective

(C) 2017 The Authors. Published by Innovare Academic Sciences Pvt Ltd. This is an open-access article under the CC BY license (http://creativecommons.org/licenses/by/4.0/) DOI: http://dx.doi.org/10.22159/ijpps.2017v9i11.19444

\section{INTRODUCTION}

Neurodegenerative diseases are characterized by progressive dysfunction and loss of neurons leading to the distinct involvement of functional systems defining clinical presentations [1] Neurodegeneration is a process involved in both neuropathological conditions and brain aging. It is known that brain pathology in the form of the cerebrovascular and neurodegenerative disease is a leading cause of death all over the world, with an incidence of about $2 / 1000$ and an $8 \%$ total death rate [2]

Studies have demonstrated that common pathology of neurodegeneration is deposition of proteins with altered physicochemical properties in the human brain. These pathological conformers are called as misfolded proteins such as accumulation and aggregation of amyloid- $\beta(\mathrm{A} \beta)$ in $\mathrm{AD}[3], \alpha$-synuclein in $\mathrm{PD}$, huntingtin protein in Huntington's disease (HD), and TDP-43 in frontotemporal dementia (FTD) and amyotrophic lateral sclerosis (ALS) [4]. In addition, it has been recognized that protein elimination pathways, like the ubiquitin-proteasome system and the autophagy-lysosome pathway, stress response proteins and chaperones have a high impact on the pathogenesis [5].

Damage of neurons also contribute to progressive long-term neurodegenerative processes, for example, the role of L-glutamate (or L-aspartate) mediated acute excitotoxicity in cerebral ischemia or status epilepticus is well known. Microglia-mediated neuroinflammation is also one of the most striking hallmarks of various neurodegenerative diseases, including PD, AD, and ALS [6].

The presently available drugs for the treatment of AD are symptomatic only and do not alter the course or progression of the underlying disease and produce adverse reactions in patients thereby having limited scope for the treatment of patients with Alzheimer's syndrome. Research is also expanding at other substances and treatments that prevent the formation of betaamyloid plaques, nerve growth factor to keep neurons healthy such as statins, antioxidants (vitamins) and folic acid, anti-inflammatory drugs [7]. The past decade has also witnessed an intense interest in herbal medicines that have long-term health-promoting qualities Herbal remedies for neurodegenerative disease is becoming more popular in the recent years as they show the possibility to slow down the brain's degeneration. The benefits derived from using herbal treatments have been very promising as they are not only as effective as prescription drugs but also have fewer side effects [8] The use of some medicinal herbs has been touted to extend beyond that of modern prescription drugs and may be used as a substitute for pharmaceutical drugs or can be used in conjunction. In the present review, attempts have been made to present the mechanistic role of few herbal medicines in the treatment and management of neurodegenerative disease [9]

\section{Search criteria}

This review included articles from 2003 to 2017 that were found in various electronic databases: PubMed, Science Direct, Scopus, Web of Science, Scirus, and Google Scholar by using the search words: neurodegenerative diseases, neuroprotection, medicinal plants, antioxidant, Alzheimer's disease, Parkinsonism, dementia, amyloid$\beta$, acetylcholinesterase. Only current articles that reported the effects of medicinal plants on neurodegenerative diseases were included in our study. Then, a comparison of the related vb mechanisms and evaluation of pharmacological effects in the treatment of disease was done.

\section{Herbal neuroprotective agents and their mechanistic pathway}

Neuroprotective agents refer to substances that are capable of preserving brain function and structure by reducing and preventing oxidative stress, mitochondrial dysfunction, inflammation, various forms of neurotoxicity (e. g. excitotoxicity), and protein deficiencies. Specific examples of things that can cause neurodegeneration include: traumatic brain injuries, drug abuse, pharmaceutical medications, schizophrenia, strokes, and dementia but the most common cause of neurodegeneration is oxidative stress and to prevent the effects of any neurodegeneration, considering neuroprotective agents may be beneficial for long-term brain health Administration of a neuroprotective agent may help minimize the 
effects of chronic conditions that could: kill brain cells, decrease brain volume, and lead to long-term functional impairment. There are more than 120 traditional medicines that are being used for the therapy of CNS disorders in Asian countries [10]. In the Indian system of medicine the following medicinal plants have shown promising activity in neuro-psycho-pharmacology:

\section{Acorus calamus}

Acorus calamus (Sweet flag) belonging to family Araceae, act as a rejuvenator for the brain and nervous system having beneficial memory enhancing the property, learning performance, and behavior modification. Acorus calamus contains a majority of $\alpha$-and $\beta$-asarone, $\beta$-asarone has the capability of suppressing betaamyloid-induced neuronal apoptosis in the hippocampus by reversal down-regulation of Bcl-2, Bcl-w, caspase-3 activation and c-Jun Nterminal kinase (JNK) phosphorylation [11]. Methanolic extracts of the roots containing $\alpha$-asarone showed inhibitory effect on AChE with an IC50 value of $188 \mu \mathrm{g} / \mathrm{ml}$ [12]. Acorus calamus has the potential of improving the function of dopaminergic nerve; by increasing striatal extracellular dopamine level and the expression of tyrosine hydroxylase in substanianigra therefore it can play role in PD. Acorus calamus also increases DJ-1 gene expression in the striatum and therefore acts as neuroprotective for PD [13].

\section{Allium sativum}

Allium sativum (family Amaryllidaceae), commonly known as garlic, is one of the most widely quoted herbs found in the old medical literatures mainly for its medicinal potentials in prevention and treatment of cardiovascular and other metabolic diseases, atherosclerosis, hyperlipidemia, thrombosis, hypertension, dementia, cancer and diabetes [14, 15]. Allicin (allyl 2-propene thiosulfinate or Diallylthiosulfinate) and alliin are the principal bioactive compounds of Allium sativum. S-allyl cysteine (SAC) is the major constituent of aged garlic extract (AGE) which is extensively studied [16, 17]. SAC has both direct and indirect antioxidant activity. Apart from decreasing lipid peroxidation and DNA fragmentation, it also reduces protein oxidation and nitration. In 1methyl-4-phenyl pyridinium (MPP) and 6-hydroxydopamine (6OHDA) models of Parkinsonism, SAC protected dopamine levels, oxidative damage and lipid peroxidation. In 3-nitro propionic acid and quinolinic acid animal models of HD, administration of SAC decreased lipid peroxidation and mitochondrial dysfunction. It also increased manganese and copper/zinc superoxide dismutase activity and prevented behavioural changes. AGE, directly and indirectly, activates expression of important genes needed for neuronal survival $[18,19]$. Allyl-containing sulfides in garlic cause the upregulation of neuroprotective proteins such as mitochondrial uncoupling proteins. Allicin also activates transient receptor potential ion channels in the plasma membrane of neurons [20,21].

\section{Bacopa monnieri}

Bacopa monnieri (Linn), commonly referred to as "Brahmi," from the plant family Scrophulariaceae is a creeping herb found in India and neighbouring tropical countries. Steroidal saponins and bacosides $\mathrm{A}$ and $B$ are the active chemical constituents responsible for improving both learning and memory [22]. Other constituents include bacopa saponins D, E and F as well as alkaloids, flavonoids, and phytosterols [23]. Bacoside A increases the activities of superoxide SOD, CAT, GPx, and glutathione reductase (GSR). As a result, the levels of glutathione (primary endogenous antioxidant conjugate) in the brain are significantly increased. Bacoside A inhibits lipid peroxidation by modulating the effects of enzymes like Hsp 70 and cytochrome P450 in the brain. It also improves the activities of adenosine triphosphatases (ATPases), maintains ionic equilibrium and restores zinc and selenium levels in the brain. The researchers found Bacopa monnieri produce a reduction in alpha-synuclein protein aggregation. Bacopa monnieri also enable the body to better cope with the deleterious mental and physical consequences of stress by elevating levels of noradrenaline (NA), dopamine (DA) and 5-hydroxytryptamine (5-HT) in the cortex and NA and 5-HT in the hippocampus [24]. Jadiya et al. investigated the effect of Bacopa monnieri on pharmacologically induced 6-hydroxydopamine (6OHDA) PD model in Caenorhabditiselegans which expressed human version of alpha-synuclein. The researchers found that the extract showed a significant 3.5-fold reduction in alpha-synuclein protein aggregation, which may be due to induction of the stress-buffer protein Hsp-70 [25, 26].

\section{Centella asiatica}

Centella asiatica belonging to family Apiaceae (Umbelliferae) has been demonstrated to possess the neuroprotective property and is used as an alternative medicine for memory improvement in the Indian Ayurvedic system of medicine for a long time [27]. The primary active constituents of Centellaasiatica are saponins (also called triterpenoids), which include asiaticosides, in which a trisaccharide moiety is linked to the aglyconeasiatic acid, madecassoside and madasiatic acid. Other components isolated are brahmoside and brahminoside, which may be responsible for CNS action [28]. Centella asiatica exhibits potent antioxidant activity, capable of scavenging free radical, reduces ferric ions, restores GSH levels by increasing the glutathione-S-transferase activity. Centella asiatica also decreases $\mathrm{A} \beta$ deposition in the brain. Chen et al. carried out a study which suggested that Centella asiatica ethanol extract can suppress $A \beta$-induced neurotoxicity by enhancing the antioxidative defence system in differentiated PC12 and IMR32 cells $[29,30]$. Amelioration of the colchicine-induced decrease in AChE activity and inhibition of nitric oxide induced neuronal damage by asiaticoside may also explain the neuroprotective effect of Centella asiatica [31,32].

\section{Curcuma longa}

Turmeric, derived from the plant Curcuma longa belonging to the Zingeberacea family, is a gold-coloured Spice that has been used as a traditional medicine. Curcumin, the principal constituent of turmeric, has several known neuroprotective actions [33]. In Alzheimer's disease, it has been shown that curcumin has the ability to bind $A \beta$ peptides, prevent aggregation of new amyloid deposits and promote disaggregation of existing amyloid deposits [34]. Scientific studies also reported that curcumin and its analogues demethoxycurcumin and bis-demethoxycurcumin can protect cells from $A \beta$-induced oxidative stress [35]. Curcumin has the ability to inhibit $A \beta$ oligomerization and fibril formation, enhance $A \beta$ uptake by macrophages and inhibits the peroxidase activity of A beta-heme complex [36]. Curcuminoids, polyphenol compounds from turmeric attenuate mitochondrial dysfunction induced oxidative stress and inflammatory responses to inflammatory cytokines, COX-2, and iNOS. Curcuminoids also bind to $A \beta$ plaques to inhibit amyloid accumulation and aggregation in the brain $[37,38]$.

\section{Celastrus paniculatus Wild}

Celastrus paniculatus Wild commonly known as Jyotishmati belongs to family Celastraceae. In the traditional system of medicine, it was administered as a powerful brain tonic, appetite stimulant, and emetic [39]. Phytochemical studies show the presence of evoninoate, a sesquiterpene, alkaloids paniculatine A, paniculatine B and wifornine F, celastrine, celapanine, celapanigine, celapagine, polyalcohol like malangunin, malkanginnol, malkanguniol and paniculatadiol, triterpenoids, sterols such as $\beta$-amyrin and $\beta$ sitosterol $[40,41]$. The scientific studies suggested that Celastrus paniculatus water extract protected neuronal cells against glutamate-induced toxicity by modulating glutamate receptor function and showed an improvement in learning and memory. It also stimulates a significant decrease in the brain levels of MDA which is an important marker of oxidative damage, with simultaneous significant increases in levels of glutathione and CAT; two endogenous antioxidants in the brain [42]. Research carried out by Jakka AL also elucidated the neurotrophic potential of flavonoids present in Celastruspaniculata Wild whole plant methanolic extract (CPPME) and treatment with CPPME demonstrated decrease in AChE and enhanced neurotrophic activity and thus, ultimately improving spatial memory formation in scopolamine-induced amnesia [43]

\section{Coriandrum sativum $\mathrm{L}$}

Coriandrum sativum L. commonly known as dhanya belongs to family Apiaceae [44]. Major phytochemical present includes flavonoids like 
quercetin 3-glucoronide; polyphenolics like caffeic acid, protocatechinic acid, and glycitin. The flavonoid content of the seeds was reported to be 12.6 quercetin equivalents/kg and the polyphenolic content was reported to be 12.2 gallic acid equivalents/kg [45, 46]. A study showed that the extract of Coriandrum sativum increased enzyme levels of SOD, GSH, CAT and total protein levels, and reduces cerebral infarct size, lipid peroxidation (LPO) and calcium levels in the experimental rat. Memory deficits induced by scopolamine and diazepam was also reversed by leaves of Coriandrum sativum [47]. It also decreases reactive changes in brain histology like gliosis, lymphocytic infiltration and cellular edema which assist the protective role in cerebrovascular insufficiency states. The leaves also show antioxidant property having 2, 2-diphenyl-1picrylhydrazyl (DPPH) radical scavenging activity, lipoxygenase inhibition and phospholipid peroxidation inhibition activity, which may also contribute to its memory enhancement effect [48].

\section{Galanthus nivalis}

Galanthus nivalis commonly known as snowdrop belongs to family Amaryllidacea. The major constituent found in bulbs and flowers of Galanthus nivalis is galantamine which is a tertiary isoquinoline alkaloid. The neuroprotective effect of galantamine is associated with the dual action of this alkaloid. The drug is a competitive and selective AChE inhibitor. It is capable of stimulating nicotinic receptors which further enhance cognition and memory [49]. The drug also modulates allosterically nicotinic acetylcholine receptors, especially $\alpha 7$ and $\alpha 3 \beta 4$ subtypes, on cholinergic neurons to increase acetylcholine release [50].

\section{Ginkgo biloba}

This species, belonging to the Ginkgoaceae family, is considered as a 'living fossil' [51]. The extract contains $24 \%$ of flavonoids fraction which is mainly composed of three flavonols, quercetin, kaempferol and isorhamnetin and $6 \%$ of terpenic lactones that include diterpenic lactones-the ginkgolides $\mathrm{A}, \mathrm{B}, \mathrm{C}, \mathrm{J}$ and $\mathrm{M}$, and a sesquiterpene tri lactone-the bilobalide [52]. Extract exhibit the neuroprotection by several mechanisms that include inhibition of membrane lipid peroxidation, anti-inflammatory effects, and direct inhibition of amyloid-b aggregation and anti-apoptotic activities. The flavonoid fraction of Ginkgo biloba (G. biloba) extract is responsible for the antioxidant and free-radical scavenging properties and bilobalide can reduce damage caused by global brain ischemia and excitotoxicity-induced neuronal death $[53,54]$. G. biloba extract significantly inhibit the AChE activity in the brain that indicates an increase in the basal level of acetylcholine [55]. Flavonoids alter a number of a biological process like their interactions with neuronal and signalling pathways, expression of proteins required for synaptic plasticity and repair, changes in cerebral blood flow, inhibition of neuropathological process in certain brain regions. A study carried out by Dash SK showed that the extract of G. biloba inhibits the production of brain $\mathrm{A} \beta$ levels by lowering cholesterol, as free and circulating free cholesterols that affect amyloidogenesis. It may also influence the formation of $A \beta$ fibrils by increasing gene expression of transthyretin that prevent $A \beta$ aggregation in vitro [56].

\section{Glycyrrhiza glabra}

Glycyrrhiza glabra (G. glabrais) commonly known as Yashti-madhuh or liquorice, belongs to family Leguminosae. The major flavonoid of G. glabra is Glabridin that possesses multiple pharmacological activities like antiviral, anticancer, anti-ulcer, anti-diabetic, antioxidant, immunomodulatory activity, antimicrobial activity, antiinflammatory activity, and anticonvulsant. Liquorice significantly improved learning and memory but the research have indicated that its consumption improves the general intelligence rather than shortterm memory [57]. Glabridin significantly decreases the level of MDA and it elevates the level superoxide dismutase and reduced glutathione in the brain [58]. A study indicated that administration of G. glabra restored the decreased levels of brain enzymes such as glutamate and dopamine and decreased AChE activity [59].

\section{Hypericum perforatum}

Hypericum perforatum ( $\mathrm{H}$. perforatum), is also known as hypericum or millepertuis is a member of the family Hypericaceae. Although it has a worldwide distribution, it is mainly native to Europe, western Asia, and northern Africa. Hyperoside is the main active component of H. perforatum. Hypericin, Kaempferol, Biapigenin and quercetin are its other constituents [60]. H. perforatum extract has also been reported to protect against enzymatic (NADPH-dependent) and nonenzymatic $\left(\mathrm{Fe}^{2+} /\right.$ ascorbate dependent) lipid peroxidation in the cerebral cortex [61]. The extract also protects brain cells from glutamate-induced cytotoxicity by reducing glutathione loss, calcium overload and ROS-mediated cell death [62]. H. perforatum ethanolic extract may improve microglial viability by reducing amyloid-beta mediated toxicity in Alzheimer's disease [63]. Hypericumperforatum inhibits acetylcholinesterase enzyme [64] and MDA formation in the brain and increases the level of SOD, CAT, GPx. According to these findings, $\mathrm{H}$. perforatum also act as an antioxidant and have the ability to bind iron ions and have scavenging action for hydroxyl radical [65].

\section{Lycopodium serratum}

Lycopodiumis is a genus of club mosses, also known as ground pines or creeping cedar, in the family Lycopodiaceae, a family of fern-allies. The leaves contain a single, unbranched vascular strand and are microphylls by definition. The genus Lycopodium (Lycopodiaceae), which produces a potential therapeutic agent, huperzine $\mathrm{A}$, for the treatment of $\mathrm{AD}$, has been extensively studied in recent years [66]. Huperzine A is an alkaloid extracted from Lycopodium serratum and has been used for centuries to treat fever, inflammation, blood disorders and schizophrenia [67]. It is a highly selective, reversible, and potent AChE inhibitor, and potency of $\mathrm{AChE}$ inhibition is similar or superior to that of physostigmine, galanthamine, donepezil and tacrine [68]. The huperzine A is a strong candidate for treatment of AD. Other potentially beneficial effects, as far as $\mathrm{AD}$ is concerned, include protection against $\mathrm{A} \beta$-induced oxidative injury and neuronal apoptosis, regulation of nerve growth factor and reduction in glutamate-induced toxicity. Huperzine A caused a significant increase in ACh levels in rat brain [69]. Huperzine A has several protective effects such as regulating amyloid precursor protein metabolism, protecting against $A \beta$ mediated oxidative stress, apoptosis and mitochondrial dysfunction, as well as anti-inflammation [70].

\section{Melissa officinalis}

The leaves of Melissa officinalis L. (Lamiaceae), also known as lemon balm, are used in traditional medicine for its nerve calming and spasmolytic effects. The leaves produce calming and soothing effects through $\mathrm{GABA}_{\mathrm{A}}$ benzodiazepine receptor [71]. Its extracts contain some compounds such as flavonoids such as quercitrin as well as apigenin, luteolin and phenolic acids. These derivatives inhibit enzymes monoamine oxidases (MAO) and $\mathrm{AChE}$, scavenge these free radicals and prevent apoptosis. The inhibition of these enzyme leads to alleviation of depression symptoms [72]. Research also suggests that Melissa officinalis exert protective activities in the PC12 cell line and might protect neurons from oxidative stress [73].

\section{Ocimum sanctum}

Ocimum sanctum, also known as 'Tulsi' in Hindi and 'Holy Basil' in English belongs to family Labiatae. The plant is also reported to contain alkaloids, glycosides, saponins, and tannins, vitamin C, and maleic acid, citric and tartaric acid [74]. A research conducted by Kusindarta et al. indicated that an ethanolic extract derived from leaves of Ocimum sanctum may stimulate and restores the expression of choline acetyltransferase in ageing human cerebral microvascular endothelial cells and could provide nerve protection and increased production of Ach may enhance the memory and cognitive ability [75]. Scientific studies reveal that the hydroalcoholic extract of Ocimum sanctum exhibits strong antioxidant activity against DPPH and hydroxyl radicals which may be due to the high amount of polyphenols and flavonoids. It inhibits lipid peroxidation, ROS generation, DNA damage, and membrane depolarization. It also decreases the lactate dehydrogenase leakage and preserved the cellular morphology, restored superoxide dismutase and catalase enzyme levels thereby preventing neuronal damage [76].

\section{Panax ginseng}

Ginseng belongs to the family of Araliaceae growing in north-eastern Asia. It is one of the most widely used herbs for boosting energy [77] Ginseng root is characterized by the presence of ginsenosides. 
Ginseng may provide protection against neurodegeneration by multiple mechanisms. The ginsenosides improve performance in a passive avoidance learning paradigm and the neuroprotection was possibly, due to its ability to suppress cellular AChE activity and enhancement of cholinergic metabolism [78]. It also produces a dose-dependent reduction in the $\beta$-amyloid deposition or glutamateinduced excitotoxicity; thereby prevent apoptosis and neuronal death. In different experimental models against PD it suppresses nitric oxide (NO) production and tissue necrotic factor-alpha (TNF$\alpha$ ) secretion, inhibits the mRNA expressions of inducible nitric oxide synthase (iNOS), TNF- $\alpha$, interleukin (IL-1 $\beta$ ), cyclooxygenase-2 (COX2) and reduces the generation of ROS [79].

\section{Rosmarinus officinalis}

Rosemary commonly known as Satapatrika, belongs to the family Lamiaceae. It contains several essential oils like carvacrol, eugenol, oleanolic acid, thymol, and ursolic acid; antioxidant constituents such as carnosic acid and ferulic acid [80]. Carnosic acid, which was first isolated from the plant by Wenkert et al. has also shown to have neuroprotective effects on cyanide-induced brain damage in cultured rodent and human-induced pluripotent stem cell-derived neurons in vitro and in vivo in various brain areas of a non-Swiss albino mouse model. Lian et al. have also shown that carnosol and rosemary essential oils inhibit the adhesion of tumour necrosis factor- $\alpha$-(TNF- $\alpha-)$ induced monocytes to endothelial cells and suppress the expression of intercellular adhesion molecule (ICAM-1) at the transcriptional level in vitro. Meng et al. reported the inhibitory effect of rosemary diterpenes on $\alpha$-secretase which is one of the major proteolytic enzymes that process amyloid precursor protein. The mechanism behind its neuroprotective actions involves not only inhibition of AChE and $\beta$-amyloid deposits as well as antiBuChE (butyrylcholinesterase) activity [81]. Apart from above activities, it possesses cytoprotective, anti-apoptotic and antiinflammatory activities that also add on to its neuroprotective mechanism [82].

\section{Salvia officinalis}

Salvia is an important genus in the Lamiaceae family reputed for improving memory and has a long history of use as memory enhancing agents $[83,84]$. The Rosmarinic acid and carnosic acid are the main active ingredient of $\mathrm{S}$. officinalis having potential pharmacological effects that include anti-inflammatory and antioxidant properties as well as weak AChE inhibitory effect $[85,86]$. It inhibits reactive oxygen species formation, lipid peroxidation, DNA fragmentation, caspase-3 activation and tau protein hyperphosphorylation [87]. All these clinical evidence may help to prevent or reduce the symptoms of dementia. One small pilot trial showed that oral administration of S. officinalis essential oil to 11 patients showing mild-to-moderate symptoms of AD significantly improved cognitive function [88].

\section{Terminalia chebula}

Terminalia chebula (T. chebula), called the "King of Medicines" in Tibet, belongs to the family Combretaceae and is one of the most important medicinal plants used in medicines of Ayurveda, Siddha, Unani and Homeopathy [89]. It contains compounds such as triterpene sarjunglucoside 1 , arjungenin and the chebulosides 1 and 2 , tannins, chebulic acid, chebulinic acid, tannic acid, ellagic acid, 2,4chebulyi- $\beta$-D-glucopyranose, gallic acid, ethyl gallate, punicalaginterflavin A, terchebin. Some flavonoids like luteolin, rutins, and quercetinetc are also present. A study reported that $\mathrm{T}$. chebula exhibit anxiolytic activity that is comparable to standard drug diazepam [90, 91]. T. chebula has good pharmacological activities relevant to dementia therapy. Sancheti et al. extracted 1, 2, 3 , 4, 6-penta-0-galloyl- $\beta$-D-glucose extracted from $T$. chebula by chromatographic methods that were reported to be the potent AChE and Butyrylcholinesterase inhibitor. Sulaiman et al. showed that ethyl acetate extract with doses of $0.001,0.005,0.015$, and $0.025 \mathrm{~g} / \mathrm{ml}$ inhibited AChE by $29.36 \%, 32.44 \%, 45.82 \%$, and $62.32 \%$, respectively. Gallic acid derived from $\mathrm{T}$. chebula exerts antiinflammatory activity via the down-regulation of the nuclear factor$\kappa \mathrm{B}(\mathrm{NF}-\kappa \mathrm{B})$ pathway in the development of inflammatory diseases, both in vitro and in vivo [92]. T. chebula also acts as an antioxidant and its activity is comparable with reference radical scavengers such as quercetin, showing $95 \%$ activity with inhibitory concentration $\left(\mathrm{IC}_{50}\right.$ ) value $2.2 \mu \mathrm{g} / \mathrm{ml}$ [93]. T. chebula fruit extract may also protect neuronal cells against ischemia, reduces NO production and death rate of microglia cells stimulated by lipopolysaccharide [94].

\section{Tinospora cordifolia}

Tinospora cordifolia (T. cordifolia) belongs to the family Menispermaceae, is commonly known as giloe. Chemical constituents derived from the plant are alkaloids, steroids, diterpenoid lactones, aliphatics, and glycosides [95]. T. cordifolia possesses a memory enhancing property which is due immunestimulation and increased synthesis of acetylcholine [96]. T. cordifolia exhibits strong free radical scavenging properties against ROS and reactive nitrogen species as studied by electron paramagnetic resonance spectroscopy. It also increases the level of reduced glutathione, expression of the gamma-glutamyl-cysteine ligase and copper-zinc superoxide dismutase genes, which plays a major role in neuronal injury during hypoxia/ischemia [97]. In addition, T. cordifolia significantly decreases the mRNA expressions of iNOS. T. cordifolia also increases the level of dopamine in the brain. Thus, $T$. cordifolia has shown to prevent the neurodegenerative changes and enhance cognition, learning and memory [98].

\section{Withania somnifera}

Withania somnifera belongs to the family Solanaceae, popularly known as Ashwagandha is considered as the Indian ginseng. The major constituents of Ashwaganda root are two withanolides, withaferin A and withanolide D. Active glyco-withanolides of Withania somnifera have a significant antioxidant function, which is accomplished by increasing the activities of SOD, CAT, and GPX. Ashwagandha is also reported as a Nervine tonic that rejuvenates the cells and boosts energy [99]. According to Rajasankara, oral treatment of PD mice with Withania somnifera root extract $(0.1 \mathrm{~g} / \mathrm{kg}$ body weight) for $7 \mathrm{~d}$ or $28 \mathrm{~d}$ elevated dopamine, 3,4-dihydroxy phenyl acetic acid and homovanillic acid levels in the corpus striatum. Furthermore, it was reported that Withania somnifera treatment increased the level of anti-apoptotic (Bcl-2) proteins and decreased the level of the pro-apoptotic (Bax) proteins in the Maneb-Paraquat-induced dopaminergic neurodegeneration model of PD. [100]. Ashwagandha extract has shown to prevent the lipid peroxidation and increase the antioxidant activity by increasing the free-radical scavenging enzymes levels in the brain. Sitoindosides VII-X and withaferin, other constituents isolated from the aqueous methanol extract of roots of Withania somnifera tend to decreased AChE activity in the brain [101].

\section{Zizyphus jujube}

Jujube fruits are used in traditional Korean and Chinese medicine to reduce anxiety and strengthen the stomach and gastrointestinal system. Jujube seeds contain large amounts of terpenoid, flavonoid, phenyl glycosides and alkaloid compounds mucilage, malic acid, citric acid, sugar, protein, organic minerals and vitamin C [102]. The herb exerts inhibitory activity against histamine release and AChE and cyclooxygenase I and II inhibitory activity. Flavonoids present exert antioxidant properties [103] Cis-9-octadecenamide (oleamide), a compound extracted from jujube is reported to have high effect on the activation of acetylcholine transferase (34.1\%) in the in vitro which leads to the increase in acetylcholine level and improves mild to moderate cognitive functions, learning and memory, motor coordination and behavioral disorders [104].

\section{CONCLUSION}

The management of neurodegenerative diseases remains a challenge in the modern medicine because of their complicated pathogenesis. Protein misfolding and their accumulation inside or outside of neurons is the key pathological feature in several neurodegenerative diseases including Alzheimer's, Parkinson's Huntington's disease. Herbal medicines are regarded as effective and promising sources of potential neuroprotective agents because of their cognitive benefits and more significantly, their mechanisms of action with respect to the fundamental pathophysiology of the diseases. Our review has acknowledged several herbal medicines 
such as such as Allium sativum, Ginkgo biloba, panaxginseng, Terminalia chebula with potential therapeutic effects for neurodegenerative diseases. It is anticipated that the information provided through this review should help the researcher to provide some evidence and conceptual detail of the benefit of a wide range of herbs as neuroprotective agents.

\section{ACKNOWLEDGEMENT}

The authors would like to extend our gratitude to traditional healers and all other informants who showed their willingness to share their knowledge on the use of herbal medicinal plants as neuroprotective agents.

\section{AUTHOR CONTRIBUTION}

Both the authors had contributed equally to the review work.

\section{CONFLICTS OF INTERESTS}

All authors have none to declare

\section{REFERENCES}

1. Kovacs GG. Current concepts of neurodegenerative diseases. Eur Med J Neurol 2014;1:78-86.

2. Baquero M, Martin N. Depressive symptoms in neurodegenerative diseases. World J Clin Cases 2015;3:682-93.

3. Alexander GE. An emerging role for imaging white matter in the preclinical risk for Alzheimer disease linking $\beta$-amyloid to myelin. JAMA Neurol 2017;74:17-9.

4. Johannes Brettschneider J, Tredici KD, Lee VMY, Trojanowski JQ. Spreading of pathology in neurodegenerative diseases: a focus on human studies. Nat Rev Neurosci 2015;16:109-20.

5. Krainc D. Clearance of mutant proteins as a therapeutic target in neurodegenerative diseases. Arch Neurol 2010;67:388-92.

6. Yu Tang. Differential roles of M1 and M2 microglia in neurodegenerative diseases. Mol Neurobiol 2016;53:1181-94.

7. Rademakers R, Neumann M, Mackenzie IR. Advances in understanding the molecular basis of frontotemporal dementia. Nat Rev Neurol 2012;8:423-34.

8. Singh N, Pandey BR, Verma P. An overview of phytotherapeutic approach in prevention and treatment of Alzheimer's syndrome and dementia. Int J Pharm Sci Drug Res 2011;3:162-72.

9. Selvam AB. Inventory of vegetable crude drug samples housed in Botanical Survey of India, Howrah. Pharmacognosy Rev 2008;2:61-94.

10. Kumar V. Potential medicinal plants for CNS disorders: an overview. Phytother Res 2006;20:1023-35.

11. Geng Y, Li C, Liu J, Xing G, Zhou L, Dong M, et al. Beta-asarone improves cognitive function by suppressing neuronal apoptosis in the beta-amyloid hippocampus injection rat. Biol Pharm Bull 2010;33:836-43.

12. Patel VS, Jivani NP, Patel SB. Medicinal plants with potential nootropic activity: a review. Res J Pharm Biol Chem Sci 2016;5:1-11.

13. Paterna JC, Leng A, Weber E, Feldon J, Bueler H. DJ-1 and Parkin modulate dopamine-dependent behavior and inhibit MPTPinduced nigral dopamine neuron loss in mice. Mol Ther 2007;15:698-704.

14. Bayan L, Koulivand PH, Gorji A. Garlic: a review of potential therapeutic effects. Avicenna J Phytomed 2014;4:1-14.

15. Chauhan NB. Effect of aged garlic extract on APP processing and tau phosphorylation in Alzheimer's transgenic model Tg2576. J Ethnopharmacol 2006;108:385-94.

16. Tatara MR, Sliwa E, Dudek K, Mosiewicz J, Studzinski T. Effect of aged garlic extract and allicin administration to sows during pregnancy and lactation on body weight gain and gastrointestinal tract development of piglets. Part I. Bull Vet Inst Pulawy 2005;49:349-55.

17. Perez Torres I, Torres Narvaez JC, Chaverri JP, Rubio-Ruiz ME, Diaz-Diaz E, Mondragon LV, et al. Effect of the aged garlic extract on cardiovascular function in metabolic syndrome rats. Molecules 2016;21:14-25.

18. Medina-Campos ON, Barrera D, Segoviano-Murillo S, Rocha D, Maldonado PD, Mendoza-Patino N, et al. S-allyl cysteine scavenges singlet oxygen and hypochlorous acid and protects
LLC-PK cells of potassium dichromate-induced toxicity. Food Chem Toxicol 2007;45:2030-9.

19. Patil TR, Patil S, Patil A, Patil ST. Garlic and neurodegenerative disorders: a review. Int J Pharmacogn Phytochem Res 2016;8:1634-44.

20. Kumar GP, Khanum F. Neuroprotective potential of phytochemicals. Pharmacogn Rev 2012;6:81-90.

21. Kumar GP, KR Anilakumar KR, Naveen S. Phytochemicals having neuroprotective properties from dietary sources and medicinal herbs. Phcog J 2015;7:1-17.

22. Kumar S, Mondal AC. Neuroprotective, neurotrophic and antioxidative role of Bacopa monnieri on CUS induced model of depression in rat. Neurochem Res 2016;41:3083-94.

23. Mahato SB, Garai S, Chakravarty AK. Bacopa saponins E and F: two jujubo geninbisdesmosides from Bacopa monniera. Phytochemicals 2000;53:711-4.

24. Jyoti A, Sharma D. Neuroprotective role of Bacopamonniera extract against aluminium-induced oxidative stress in the hippocampus of rat brain. Neurol Toxicol 2006;27:451-7.

25. Jadiya P, Khan A, Sammi SR, Kaur S, Mir SS, Nazir A. Antiparkinsonian effects of Bacopa monnieri: insights from transgenic and pharmacological Caenorhabditiselegans models of Parkinson's disease. Biochem Biophys Res Commun 2011;413:605-10.

26. Aguiar S, Borowski T. Neuropharmacological review of the nootropic herb Bacopa monnieri. Rejuvenation Res 2013;16:313-26.

27. Golla P, Tirupathi H. To evaluate and compare the antidepressant activity of Centella asiatica in mice by using forced swimming test. Int J Basic Clin Pharmacol 2016;5:2017-20.

28. Gohil KJ, Patel JA, Gajjar AK. Pharmacological review on Centella asiatica: a potential herbal cure-all. Indian J Pharm Sci 2010;72:546-56.

29. Chen CL, Tsai WH, Chen CJ, Pan TM. Centella asiatica extract protects against amyloid b1e40-induced neurotoxicity in neuronal cells by activating the antioxidative defence system. Afr J Tradit Complementary Altern Med 2016;6:362-9.

30. Soumyanath A, Zhong YP, Gold SA, Yu X, Koop DR, Bourdette D, et al. Centellaasiatica accelerates nerve regeneration upon oral administration and contains multiple active fractions increasing neurite elongation in vitro. J Pharm Pharmcol 2005;57:1221-9.

31. Kumar A, Seghal N, Padi SV, Naidu PS. Differential effects of cyclooxygenase inhibitors on intra cerebroventricular colchicine-induced dysfunction and oxidative stress in rats. Eur J Pharmacol 2006;551:58-66.

32. Jin SG, Chuen LC, Koo MWL. Inhibitory effects of Centellaasiatica water extract and asiaticoside on inducible nitric oxide synthase during gastric ulcer healing in rats. Planta Med 2004;70:1150-4.

33. Zhou H, Beevers CS, Huang S. The targets of curcumin. Curr Drug Targets 2011;12:332-47.

34. Garcia AM, Borrelli LA, Rozkalne A, Hyman BT, Bacskai BJ. Curcumin labels amyloid pathology in vivo, disrupts existing plaques, and partially restores distorted neurites in an Alzheimer mouse model. J Neurochem 2007;102:1095-104.

35. Ahmed T, Gilani AH. A comparative study of curcuminoids to measure their effect on inflammatory and apoptotic gene expression in an $A \beta$ plus ibotenic acid-infused rat model of Alzheimer's disease. Brain Res 2011;1400:1-18.

36. Ono K, Hasegawa K, Naiki H, Yamada M. Curcumin has potent antiamyloidogenic effects for Alzheimer's beta-amyloid fibrils in vitro. J Neurosci Res 2004;75:742-50.

37. Kim DS, Kim JY, Han Y. Curcuminoids in neurodegenerative diseases. Recent Pat CNS Drug Discovery 2012;7:184-204.

38. Maiti P, Manna J. Dietary curcumin: a potent natural polyphenol for neurodegenerative diseases therapy. Anat Physiol 2015;1:1-26.

39. Basu NK, Pabrai PR. Chemical investigation of Celastrus paniculata willd. J Am Pharm Assoc 2006;35:272-83.

40. Yasu LU, Yang S, Zou Z, Chen H, Zhen X, Zhongemei Z, et al. Evoninoate sesquiterpene alkaloids from the stem of Celastrus paniculatus. Heterocycl 2006;68:1241-7.

41. Borbone N, Borrelli F, Montesano D, Izzo AA, Marino SD, Capasso R. Identification of a new sesquiterpene polyol ester from Celastrus paniculatus. Planta Med 2007;73:792-4. 
42. Arora N, Rai SP. Celastrus paniculatus, an endangered Indian medicinal plant with miraculous cognitive and other therapeutic properties: an overview. Int J Pharm Biol Sci 2012;3:290-303.

43. Jakka AL. A study on nootropic activity of Celastrus paniculata Wild whole plant methanolic extract in rats. Asian J Pharm Clin Res 2016;9:336-41.

44. Patel VS, Jivani NP, Patel SB. Medicinal plants with potential nootropic activity: a review. Res J Pharm Biol Chem Sci 2016;5:1-11.

45. Bhat S, Kaushal P, Kaur M, Sharma HK. Coriander (Coriandrum sativum L.): processing, nutritional and functional aspects. Afr J Plant Sci 2014:8:25-33.

46. Deepa B, Anuradha CV. Antioxidant potential of Coriandrum sativum L. seed extract. Indian J Exp Biol 2011;49:30.

47. Vekaria RH, Patel MN, Bhalodiya PN, Patel V, Desai TR, Tirgar PR. Evaluation of the neuroprotective effect of Coriandrum sativumlinn against ischemia-reperfusion insult in brain. Int J Phytopharmacol 2012;3:186-93.

48. Liu QF, Jeong H, Lee JH, Hong YK, Oh Y, Kim YM, et al. Suppresses Aß42-induced ROS increases, glial cell proliferation, and ERK activation. Am J Chin Med 2016;44:1325-47.

49. Wattmo C, Jedenius E, Blennow K, Wallin AK. Dose and plasma concentration of galantamine in Alzheimer's disease-clinical application. Alzheimer's Res Ther 2013;5:1-9.

50. Prvulovic D, Hampel H, Pantel J. Galantamine for Alzheimer's disease. Expert Opin Drug Metab Toxicol 2010;6:345-54.

51. Yuan Q, Wang CW, Shi J, Lin Z. Effects of Ginkgo biloba on dementia: an overview of systematic reviews. J Ethnopharmacol 2017;195:1-9.

52. Birks J, Grimley EJ. Ginkgo biloba for cognitive impairment and dementia. Cochrane Database Syst Rev 2009;18:CD003120.

53. DeKosky ST, Williamson JD, Fitzpatrick AL, Kronmal RA, Lves DG, Saxton JA, et al. Ginkgo biloba for prevention of dementia: a randomized controlled trial. JAMA 2008;300:2253-62.

54. Wu Y, Sun J, George J, Ye H, Cui Z, Li Z, et al. Study of neuroprotective function of Ginkgo biloba extract (EGb761) derived-flavonoid monomers using a three-dimensional stem cellderived neural model. Biotechnol Progress 2016;32:735-44.

55. Brondino N, Silvestri AD, Re S, Lanati N, Thiemann P, Verna A, et al. A systematic review and meta-analysis of Ginkgo biloba in neuropsychiatric disorders: from ancient tradition to modernday medicine.J Evidence-Based Complementary Altern Med 2013. http://dx.doi.org/10.1155/2013/915691

56. Dash SK. Ginkgo biloba in Alzheimer's disease. Austin J Clin Neurol 2015;2:1028.

57. Teltumbde AK, Wahurwagh AK, Lonare MK, Nesari TM. Effect of yashtimadhu (Glycyrrhiza glabra) on intelligence and memory function in male adolescents. Scholars J Appl Med Sci 2013;1:90-5.

58. Yu XQ, Xue CC, Zhou ZW, Li CG, Du YM, Liang J, et al. In vitro and in vivo neuroprotective effect and mechanisms of glabridin, a major active isoflavan from Glycyrrhiza glabra (licorice). Life Sci 2008;82:68-78.

59. Muralidharan P, Balamurugan G, Babu V. Cerebroprotective effect of Glycyrrhiza glabra Linn. root extract on hypoxic rats. Bangladesh J Pharmacol 2009; 4:60-4.

60. Shrivastava M, Dwivedi LK. Therapeutic potential of hypericumperforatum: a review. Int J Pharma Sci Res 2015;6:4982-8.

61. Benedi J, Arroyo R, Romero C, Martin-Aragon S, Villar AM. Antioxidant properties and protective effects of a standardized extract of Hypericum perforatum on hydrogenperoxide-induced oxidative damage in PC12 cells. Life Sci 2004;75:1263-76.

62. Oliveira AI, Pinho C, Sarmento B, Dias AC. Neuroprotective activity of Hypericum perforatum and its major components. Front Plant Sci 2016; 7:1004.

63. Butterfield DA, Reed T, Newman SF, Sultana R. Roles of amyloid beta-peptide-associated oxidative stress and brain protein modifications in the pathogenesis of Alzheimer's disease and mild cognitive impairment. Free Radical Biol Med 2007;43:658-77.

64. Altun ML, Yilmaz BS, Orhan IE, Citoglu GS. Assessment of cholinesterase and tyrosinase inhibitory and antioxidant effects of Hypericum perforatum L. (St. John'swort). Ind Crops Prod 2013;43:87-92.
65. Alia M, Mateos R, Ramos S, Lecumberri E, Bravo L, Goya L. Influence of quercetin and rutin on growth and antioxidant defense system of a human hepatomacellline (HepG2). Eur J Nutr 2006;45:19-28.

66. Ding $\mathrm{R}, \mathrm{Fu} \mathrm{JG}, \mathrm{Xu}$ GQ. Divergent total synthesis of the Lycopodium alkaloids huperzine $A$, huperzine $B$, and huperzine. U J Org Chem 2014;79:240-50.

67. Bai D. Development of huperzine A and B for treatment of Alzheimer's disease. Pure Appl Chem 2007;79:469-79.

68. Chu D, Tian J, Liu W. Poly(lactic-co-glycolic acid) microspheres for the controlled release of huperzine a: in vitro and in vivo studies and the application in the treatment of the impaired memory of mice. Chem Pharm Bull 2007;55:625-8.

69. Zangara A. The psychopharmacology of huperzine a: an alkaloid with cognitive enhancing and neuroprotective properties of interest in the treatment of Alzheimer's disease. Pharmacol Biochem Behav 2003;75:675-86.

70. Zhang HY, Zheng CY, Yan H, Wang ZF, Tang LL, Gao X, et al. Potential therapeutic targets of huperzine A for Alzheimer's disease and vascular dementia. Chem Biol Interact 2008;175:396-402.

71. Filho JE, Silveira D, Soares AC, Carneiro FP, Assis MS. Effects of lemon balm (Melissa officinalis) on behavioral deficits and memory impairment of rats surviving sepsis. J Med Plants Res 2017;11:153-60.

72. Timonen M, Liukkonen T. Management of depression in adults. Br Med J 2007;336:435-9.

73. Akhondzadeh S, Noroozian M, Mohammadi M, Ohadinia S, Jamshidi AH, Khani M. Melissa officinalis extract in the treatment of patients with mild to moderate Alzheimer's disease: a double-blind, randomised, placebo-controlled trial. J Neurol Neurosurg Psychiatry 2003;74:863-6.

74. Cohen MM. Tulsi-Ocimum sanctum: a herb for all reasons. J Ayurveda Integr Med 2014;5:251-9.

75. Kusindarta DL, Wihadmadyatami H, Haryanto A. Ocimum sanctum Linn stimulate the expression of choline acetyl transferase on the human cerebral microvascular endothelial cells. Vet World 2016;9:1348-54.

76. Venuprasad MP, Kumar KH, Khanum F. Neuroprotective effects of hydroalcoholic extract of Ocimum sanctum against $\mathrm{H}_{2} \mathrm{O}_{2}$ induced neuronal cell damage in SH-SY5Y cells via its antioxidative defence mechanism. Neurochem Res 2013;38:2190-200.

77. Hong-Yan Pan, Yang Qu, De-Qiang Dou. Antioxidant activity of ginseng cultivated under mountainous forest with different growing years. J Ginseng Res 2013;37:355-60.

78. Kshirsagar A, Mohite R, Aggrawal AS, Suralkar U. Hepatoprotective medicinal plants of ayurveda-a review. Asian J Pharm Clin Res 2011;4:1-8.

79. Chen XC, Zhu YG, Zhu LA, Huang C, Chen Y, Chen LM, et al. Ginsenoside Rg1 attenuates dopamine-induced apoptosis in PC12 cells by suppressing oxidative stress. Eur J Pharmacol 2003;473:1-7.

80. Vilma Papajani, Entela Haloci, Enkelejda Goci, Rezarta Shkreli, Stefano Manfredini. Evaluation of antifungal activity of origanum vulgare and Rosmarinus officinalis essential oil before and after inclusion in $\beta$-cyclodextrine. Int J Pharm Pharm Sci 2015;7:271-3.

81. Habtemariam S. The therapeutic potential of rosemary (Rosmarinus officinalis) diterpenes for Alzheimer's disease. J Evidence-Based Complementary Altern Med 2016. http://dx.doi.org/10.1155/2016/2680409

82. Park SE, Kim S, Sapkota K, Kim SJ. Neuroprotective effect of Rosmarinus officinalis extracts on the human dopaminergic cell line. Cell Mol Neurobiol 2010;30:759-67.

83. Tapsell LC, Hemphill I, Cobiac L, Patch CS, Sullivan DR, Fenech $M$, et al. Health benefits of herbs and spices: the past, the present, the future. Med J Aust 2006;185:S4-24.

84. Imanshahidi $\mathrm{M}$, Hosseinzadeh $\mathrm{H}$. The pharmacological effects of Salvia species on the central nervous system. Phytother Res 2006;20:427-37.

85. Sallam A, Mira A, Shour A, Shimizu K. Acetylcholine esterase inhibitors and melanin synthesis inhibitors from Salvia officinalis. Phymed 2016;23:1005-11. 
86. Eidi M, Eidi A, Bahar M. Effects of Salvia officinalis L. (sage) leaves on memory retention and its interaction with the cholinergic system in rats. Nutrition 2006;22:321-6.

87. Tildesley NT, Kennedy DO, Perry EK, Ballard CG, Wesnes KA, Scholey AB. Positive modulation of mood and cognitive performance following administration of acute doses of Salvia lavandulaefolia essential oil to healthy young volunteers. Physiol Behav 2005;83:699-709.

88. Akhondzadeh S, Noroozian M, Mohammadi M, Ohadinia S, Jamshidi AH, Khani M. Salvia officinalis extract in the treatment of patients with mild to moderate Alzheimer's disease: a double-blind, randomized and placebo-controlled trial. J Clin Pharm Ther 2003;28:53-9.

89. Lee DY, Kim HW, Yang H, Sung SH. Hydrolyzable tannins from the fruits of Terminalia chebula Retz and their $\alpha$-glucosidase inhibitory activities. Phytochem 2017;137:109-16.

90. Krishnaveni M, S Mirunalini S. Amla-the role of ayurvedic therapeutic herb in cancer. Asian J Pharm Clin Res 2011;4:13-7.

91. Chandrashekar R, Manohar VR, Rao SN. Acute anxiolytic effect of aqueous extract of fruits of Terminalia chebula (AETC) in mice. Int J Pharm Biol Sci 2012;3:673-7.

92. Amir R Afshari, Hamid R Sadeghnia, Hamid Mollazadeh. A review on potential mechanisms of Terminalia chebula in Alzheimer's disease. Adv Pharmacol Sci 2016 http://dx.doi.org/10.1155/2016/8964849

93. Arya V, Bhardwaj A, Sharma V. Pharmacology of some antioxidant plants from district Kangra Himachal pradesh-a review. Int J Curr Pharm Res 2011;3:26-31.

94. Gaire BP, Pandit NJ, Lee D, Song J, Kim JY, Park J, et al. Terminalia chebula extract protects OGD-R induced PC12 cell death and inhibits LPS induced microglia activation. Mol 2013;18:3529-42.

95. Rawal Avinash K, Muddeshwar Manohar G, Biswas Saibal K Rubiacordifolia, Fagonia cretica Linn and Tinospora cordifolia exert neuroprotection by modulating the antioxidant system in rat hippocampal slices subjected to oxygen-glucose deprivation. BMC Complementary Altern Med 2004;4:1-9.

96. Shanish AA, Santhivardhan C, Elango K, Jayasankar K, Kumar MN, Roy S, et al. Neuroprotective effect of Tinospora cordifolia ethanol extract on 6-hydroxy dopamine-induced Parkinsonism. Indian J Pharmacol 2014;46:176-80.

97. Bairy KL, Rao Y, Kumar KB. Efficacy of Tinospora cordifolia on learning and memory in healthy volunteers: a double-blind, randomized, placebo-controlled study. Iranian J Pharmacol Ther 2004;3:57-60.

98. Antony AS, Chinni S, Kannan E, Kosaraju J, Kumar MNS, Roy PD. Neuroprotective effect of Tinospora cordifolia ethanol extract on 6-hydroxy dopamine-induced Parkinsonism. Indian J Pharmacol 2014;46:176-80.

99. Sharma S, Veena Sharma V, Sharma S. Therapeutic potential of hydromethanolic root extract of Withania somnifera on neurological parameters in swiss albino mice subjected to lead nitrate. Int J Curr Pharm Res 2010;3:52-6.

100. Singh N, Rai SN, Singh D, Singh SP. Withania somnifera shows ability to counter Parkinson's Disease: An Update. SOJ Neurol 2015;2:1-4.

101. Kumar P, Kumar A. Possible neuroprotective effect of Withania somnifera root extract against 3-nitropropionic acid-induced behavioral, biochemical, and mitochondrial dysfunction in an animal model of Huntington's disease. J Med Food 2009;12:591-600.

102. Koetter U, Barrett M, Lacher S, Abdelrahman A, Dolnick D. Interactions of magnolia and ziziphus extracts with selected central nervous system receptors. J Ethnopharmacol 2009;124:421-5.

103. Chang SC, Hsu BY, Chen BH. Structural characterization of polysaccharides from Zizyphus jujubaand evaluation of antioxidant activity. Int J Biol Macromol 2010;47:445-53.

104. Jivad N, Zahra Rabiei Z. A review study on medicinal plants used in the treatment of learning and memory impairments. Asian Pac J Trop Biomed 2014;4:780-9. 